\title{
Mobile-Apps Development for Biodiesel Distribution Tracking System and Supply Chain Monitoring
}

\author{
M. Iman Santoso \\ Department of Transport-System \& Logistic, Duisburg-Essen University \\ 47058 Duisburg, Germany \\ E-mail: muhammad.santoso@stud.uni-due.de (Corresponding Author)
}

\author{
Bernd Noche \\ Department of Transport-System \& Logistic \\ Duisburg-Essen University, 47058 Duisburg, Germany \\ E-mail: bernd.noche@uni-due.de
}

\begin{abstract}
Biodiesel is considered as the most prominent alternative to replacing or complement petroleum-diesel in the future. It is slowly gaining its importance in our daily life. Nevertheless, there are several problems emerged in the biodiesel supply chain, e.g. biodegradability, quality control, disturbance in the distribution of biodiesel, interrupted feedstock, supply and lack of governance. A new approach of biodiesel supply chain management has been developed based on mobile-application to overcome such problems. Determining the fact that biodiesel is degradable over time, the system also possessed by feature to maintain the biodiesel quality during transport, besides bringing-out simple and user-friendly supply-trading application on hand to hand. A wide range of biodiesel supply chain monitoring, distribution tracking and quality checking are demonstrated during the process of ordering, stocking, buying and sending biodiesel. The mobile-application has been tested for performance analysis on processor, battery and data usage. All menus, performance test and survey show good responses although at the security aspect is found the necessity of extra-development. Further analysis indicates that such system also fit for feedstock plantation, cultivation, harvesting and procurement. Overall, this method is worthy suggested to be implemented on the accreditation board of biodiesel that manages the entire supply, orders, trades and quality of biodiesel from upstream to the downstream.
\end{abstract}

Keywords: biodiesel, supply chain, mobile-application, distribution, tracking

\section{INTRODUCTION}

Biodiesel is classified as part of biofuel that is known by solid, liquid or gaseous fuels derived from organic matter using trans-esterification process. Biodiesel industry uses abbreviation of "B" to indicate the percentage of biodiesel in a gallon of fuel. Thus, the composition of $6 \%$ and $20 \%$ of biodiesel in a blend with petro-diesel is referred to "B6" and "B20". Pure biodiesel that already derived from the transesterification process is called "B100". Biodiesel is also referred to as FAME (Fatty Acid Methyl Ester). However, biodiesel is not an instant product. Continual from a farmcultivation until production, blending, distribution and retail, it is running through lengthy process.

The main problem of biodiesel supply-chain remains on its degradability over time, mainly influenced by temperature, presence of light, metal, oxygen and the condition of storage. Refers to that problem, there are several studies on the biodiesel stability that can be addressed to the following segment. According to Zhang (1988), biodiesel is categorized as an alternative diesel fuel consisting of alkyl monoester of fatty acids derived from vegetable oils. Typical Biodiesel characteristic is renewable, reduces the emission of some pollutants, and is also readily biodegradable in the environment. Bondioli (1995) and Thompson (1998) have recorded degradation of rapeseed oil methyl ester (RME) under different storage conditions, using different variable of acidity peroxide value and viscosity have been studied. It is reported that acid value $(\mathrm{AV})$, peroxide value (PV) and viscosity (v) increased with time. Monyem (2000) and Mittelbach (2001) have discovered that the biodiesel oxidation is influenced by several factors, such as elevated temperature, light, the presence of metals, and other conditions that may accelerate oxidation. High temperature, together with air exposure, rapidly grows the biodiesel degradation rate, while the temperature and air exposure had little effect on biodiesel degradation (Leung, 2006). In line with the degradation issues of common biodiesel distribution that previously mentioned, this paper is focusing its study on the Indonesian biodiesel industry in the term of supply chain. Indonesian biodiesel also faces several problems experienced by Indonesian state own oil operator PERTAMINA (2012) through the following points description: 1) Empirical proven that biodiesel cannot be stored for too long and can be easily damaged by water environment. 2) Lack of governance and quality verification test. 3) Some fuel terminals has small throughput, which is not very economical if infrastructure is built such as shore tank biodiesel. In this case, biodiesel and petro-diesel are blended from the tank biodiesel-truck directly. Regularly, it leads a disturbance in the distribution of biodiesel or even delay in supply biodiesel. 4) Dissolution supply for the region that has no feedstock or remote districts. Moreover, Indonesian Chamber of Commerce also determine industrial requirements of biodiesel by following criteria: 1) Biodiesel has to be had compatible on quality or better than normal diesel fuel, 2) Continuity of feedstock supply, 3) End product distribution enhancement, 4) Planned and measurable conversion program, 5) Continuous supplies to the wholesaler and interconnection of the information flow (Wirawan, 2008). 
Aforementioned problems on Indonesian Biodiesel are caused by remaining difficulty on the biodiesel quality control, monitoring and a lack of coordination on the biodiesel supply chain due to poor information-system. In order to coordinate, anticipate and solve such problems, this paper propose integrated of information sharing concept and control-tower system that involves multiple value chains and distribution tracking using mobile-application (mobile-app) managed by web-center database. Mobile-application (mobile-app) and the data-center supported by "geographic information system" (GIS) are offered to overcome those issues. The GIS-based information-sharing accommodate the demand of shared fast, purposes, principle and accurate information from a wide range of operating areas for all supply chain members in the biodiesel industry, such as raw-material suppliers, grain-transporters, biodieselproducers, petro-diesel refinery stations, blending-stations, biodiesel-blending-transporters and pump-stations, etc. Further detail of the proposed system is described on the next sections.

\section{INFORMATION SHARING ON THE BIODIESEL SUPPLY CHAIN AND MONITORING}

Supply chain management (SCM) encompasses the preparation and administration of all logistic activities. It unites supply and demand coordination inside and over corporations (CSCMP, 2014). In order to gain its role, SCM is dealing with the information sharing and integration. The main idea is to grant everyone includes in the flow of goods to make a decision based in the latest and real-time information from whomever on the spacious area of supply chain. At the very beginning of SCM invented, many information systems built to manage and analyzed logistical and inventory processes but rather not integrated (Davenport, 2004). The significance of information-sharing addressed by Cachon (2000), Stock (2001), Zha (2005), Nunes (2006) as a strategic to leverage supply chain in the world global competition, improving efficiency, producing smooth-transaction and reducing the cost of supply chain. Simatupang (2005), Wu (2004) and Hsu (2008) report that information-sharing enhances buyer and supplier commitment and their interconnection. It eases supplier, manufacturer, retailer and trading partners to respond demand fluctuation and managing supply chain performance. Lee (1998) describes information shared on the supply chain in the area of inventory, sales, demand forecast, order status and production schedule. Later, Pandey (2010) add more four categories of information shared in the field of market development, future plan, production cost and technology know-how. In 2013, Lotfi (2013) summarize the type of information-shared in supply chain categorized as: 1) Inventory Information; 2) Sales Data; 3) Sales Forecasting; 4) Order Information; 5) Product Ability Information; 6) Exploitation Information of New Products; and 7) Other Information.

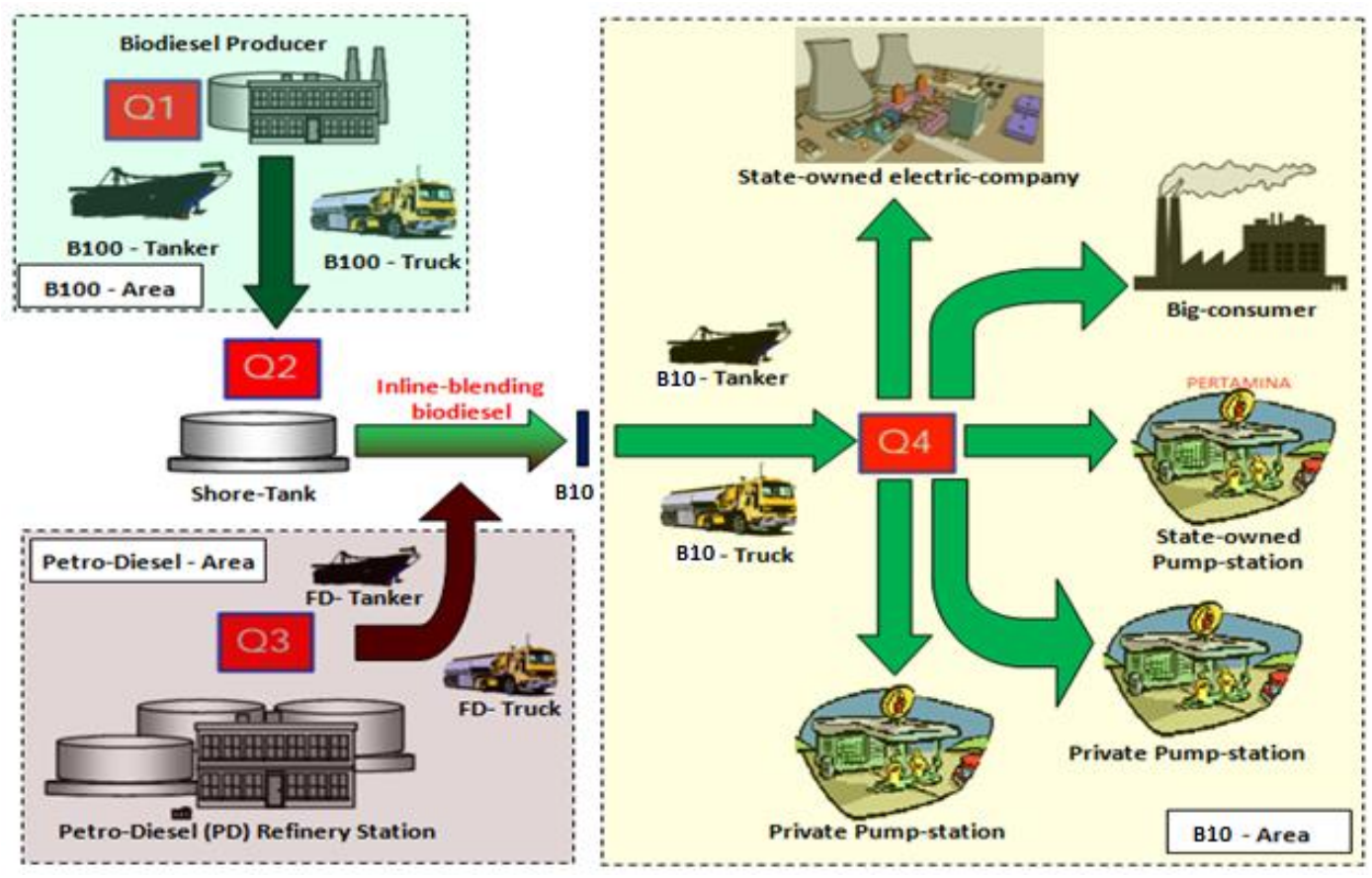

Figure 1 Indonesian Biodiesel Supply Chain (modified from (PERTAMINA, 2012))

Information-sharing becomes valuable in the supply chain of biodiesel because of some problems that have been mentioned previously. In the case of biodiesel supply chain in Indonesia, significance an information-sharing can be explained by Figure 1. National Oil and Gas Mining Company of Indonesia (Pertamina) performs quality control as shown in Figure 2. In every quality check-point (Q1 Q4), Pertamina take Biodiesel sample from the tank and held laboratory tests. Only products that have passed a quality inspection moved to the next stage. First of all, purebiodiesel is produced, then quality-checks performed by manufacturer on Q1 (the first - quality check). Furthermore, the producers send B100 (pure-biodiesel) to the distributioncenters (Pertamina-Depot) around the nation. The sitemanager checks the 7 parameters of B100 before it is stored in the shore-tanks of the distribution-center on Q2 (the second - quality check). Q3 (the third - quality check) examine the quality parameters of petro-diesel from the 
refinery-station that will be mixed to the biodiesel. Afterwards, Pertamina blend B100 and petro-diesel to reach $10 \%$ biodiesel and $90 \%$ petro-diesel composition in their Depot. Pertamina executes Q4 (the fourth - quality check) after shipping the blending-biodiesel B10 but shortly before accepted by the retailers (pump-stations), industrialconsumers and state-own electrical company. The whole processes need accurate information sharing to ensure successor-stage get appropriate data of biodiesel-quality from the previous-stage. Thus, every chain of supply can monitor the biodiesel distribution from stage to stage. The producers and refinery-stations get vision of how much biodiesel ordered by consumers and on the other side, retailers, consumers and distributors could retract data of how many stock remaining on the shore-tanks, how long the biodiesel still have its tolerable-performance, when their order will come, etc.

\section{RESEARCH METHODOLOGY AND SYSTEM DESIGN}

\subsection{Research Methodology}

The research conducts in the corridor of supply chain management that considers several aspects of governance, biodiesel distribution, online-transaction and trading. The following methodologies are carried out to pursue the research objectives, i.e.: 1) Literature Review, 2) SupplyChain Software Development Process Model, 3) Performance-analysis and 4) Questioner.

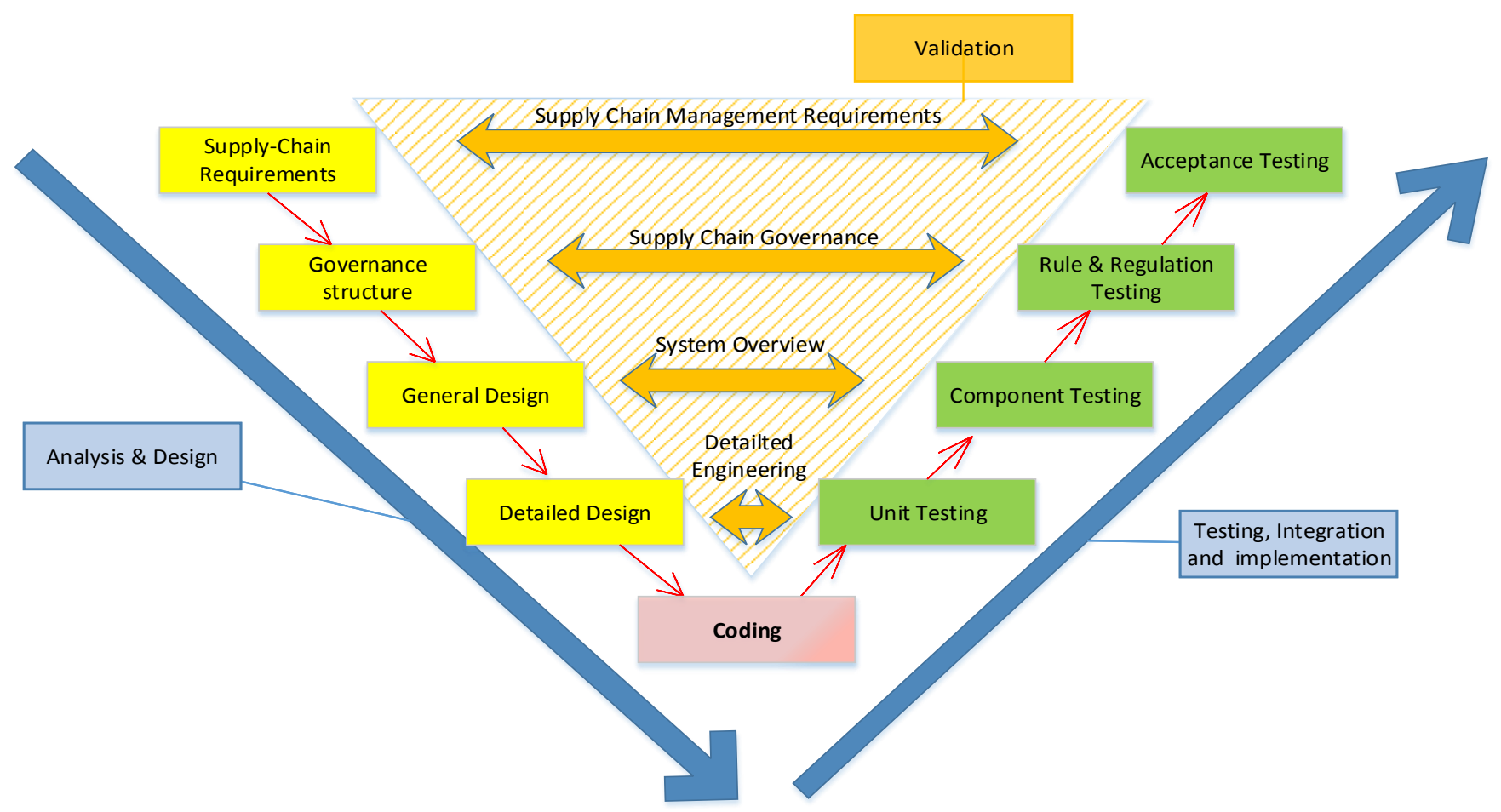

Figure 2 Supply-Chain Software Development Process (Santoso, 2014)

Supply-Chain Software Development Process is a pattern to develop software/application system in the field of supply chain which consider several aspects, like supply chain requirements, governance, validation, coding and testing (Santoso, 2014). This method modifies V-model of software development life-cycle using supply-chain and governance approach. Employing such system makes the research more systematic and well-documented (Figure 2). Moreover, network configurations that can be customized would provide an element of flexibility. Raw-material suppliers, grain-transporters, biodiesel-producers, petrodiesel refinery stations, blending-stations, biodieselblending-transporters and pump-stations owners could sit together to determine the initial requirements of the systemdesign upfront and adjusted to the desired logistics strategy. As biodiesel supply chain member, they have to setup the governance structure, rules, regulations and hierarchyprivilege of each member. Then, the system developer has to validate the requirements to match with the governance structure using a rule-testing regulation.

\subsection{System Design}

Design of the system is carried out in the following stages: tool selection, determine general systems connection, create database-table and plan applications, split workpackage of programming into several modules and design of mobile-apps menu and the web-appearance.

Tools are major utility for software development, which provide an interface that helps in achieving the desired application requirements. Tools that are used in this research are: a) Android-OS, b) Android-SDK, c) IDE: Eclipse, d) Google API, e) Java, f) PHP, g) MYSQL, h) GCM: Google Cloud Messaging, i) Android Emulator: Genymotion.

\section{RESULT, DISCUSSION AND ANALYSIS}

\subsection{Result}

"Biotrack" is the name of the application that has been developed in this research as the tool for biodiesel distribution tacking system and supply chain monitoring. 
The application has been developed for meeting two different aspects, i.e. the aspect of the supply chain and the aspect of distribution tracking.

\subsubsection{Supply Chain Monitoring Aspect}

The transaction started by stock management of the biodiesel. In this research, the developed application has the capability to track the stock and its location as explained below. The flow of the developed application starts with the registration of the user. A user can be registered in three categories. They are supplier, customer or transporter. A supplier needs to keep track of the stock before the delivery of the order from the customer can be made. Another main part of the storage management is the storage location. Since, the distribution of the biodiesel always starts from the stock location to the delivery location. It is mandatory for a customer to have knowledge about the source of his delivery to be able to track their delivery.

Figure 3a depicts the overview of the stock detail. A supplier is able to enter new stock details or update the existing. The main information units have been taken as the entry fields in the application. The stock-name needs to be entered along with the quantity and the quality of the stock. The stock-location has to be entered, since it plays a vital role on the delivery tracking.

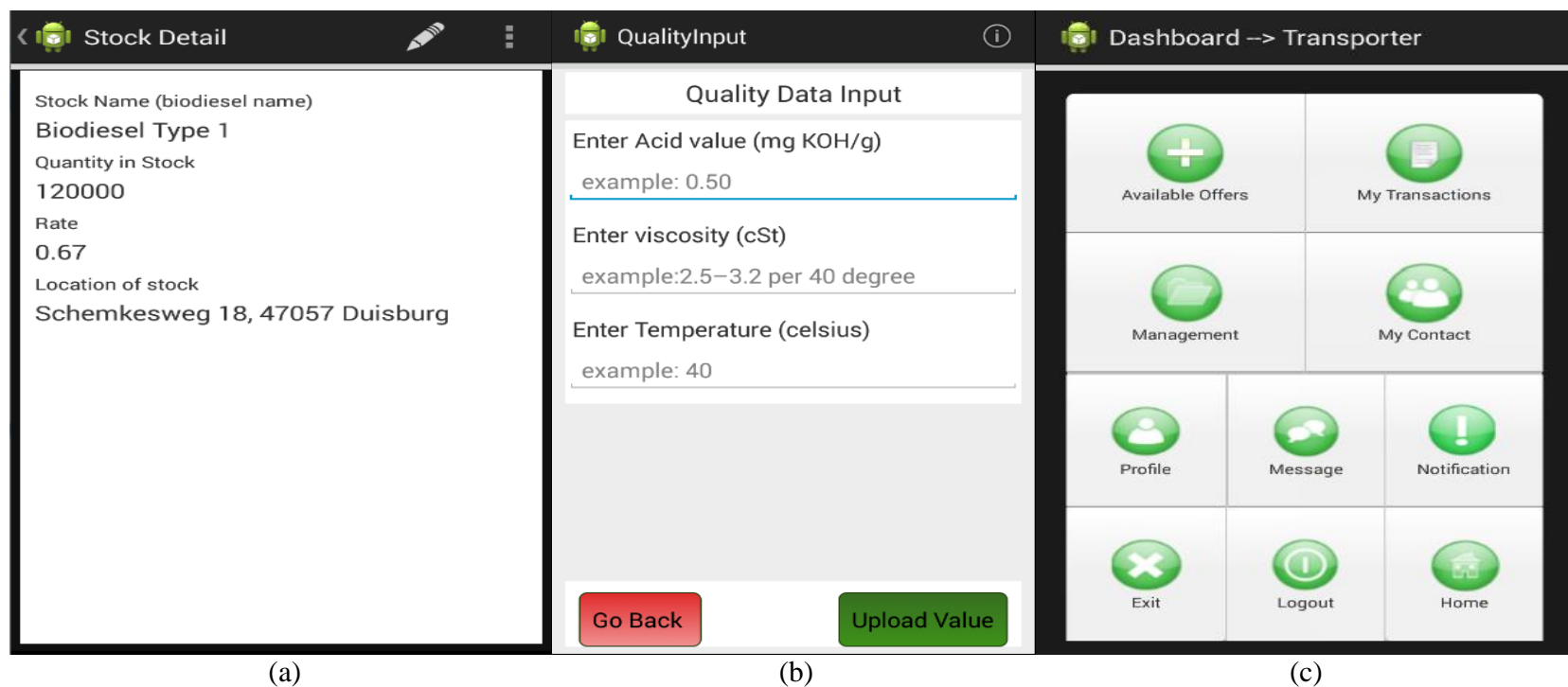

Figure 3 a) Stock Detail Screen, b) Quality Input, c) Dashboard

\subsubsection{Distribution Tracking Aspect}

The distribution tracking-system is the location tracking of the transporter-vehicle which is delivering the product. It is already discussed previously that the quality of the biodiesel degrades when time passes by. Hence, the mobile application developed in this mobile-app is capable of tracking the both parts, the location of the delivery vehicle (Figure 4a) as well as the quality of the biodiesel
(Figure 4b). The transporter needs to enter manually the acid value, the viscosity or the temperature of the biodiesel time to time (see the input-panel on the Figure $\mathbf{3 b}$ ). It is assumed that these values can be read from the cab of the truck. These quality variables values as well as currentlocation will be saved in the central-database for further analysis.

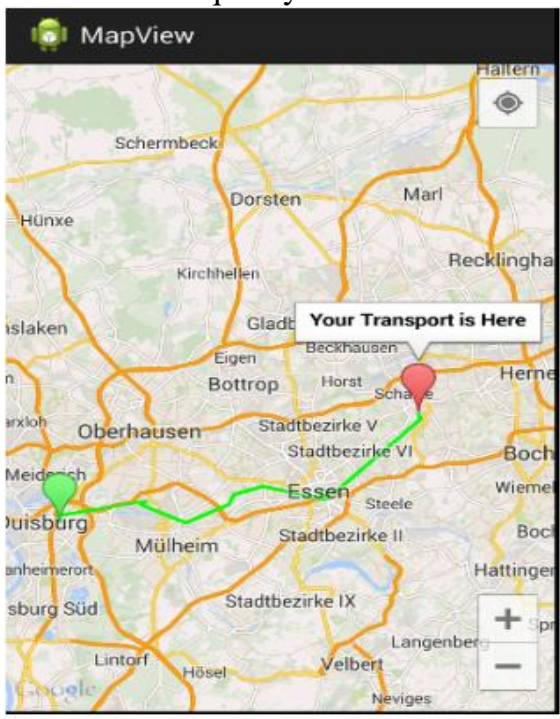

(a)

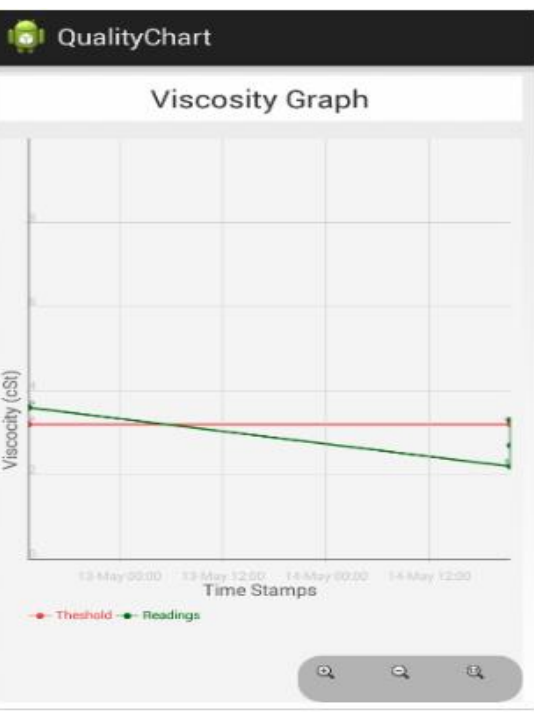

(b)

Figure 4 a) Location Tracking System, b) Quality Tracking 


\subsubsection{Application Overview}

This application starts with a home screen. A user can either log-in to the system or create a new account. Once a user is successfully logged-in, a dashboard with different functionality will be shown (Figure 3c). Dashboard is the main screen of the application and consist of the following menus: 1) Profile: This feature is just the user profile display page, a user can either see or edit few information like email, contact address, telephone number etc. 2) Message: This is the internal implementation of the mailing function in the application. A user can easily send/receive message his trading partners using this feature. Messages are saved in the Biotrack database. 3) Notification: Notifications are used just in case of emergency. A user can push notification to the server in case of emergency, 4) My Contact: This feature gives access to overview the trading partners whenever they have successfully started any transaction, 5) Management: This feature has been further divided into different sub features. If a user is logged in as a supplier then, he can manage his stocks and his business sites. If a customer is logged in then he can manage his business location. And finally if there is a transporter then he can manage his vehicles. User's current location viewing is set as a common feature inside management, 6) Offers: This section also depends on the type of the user logged in. A supplier can see if there is any new order placed, whereas customer and transporter can see place a new order or apply for new transportation respectively, 7) Transaction: This is the feature, which actually deals with the main trading.

\subsubsection{Billing and Invoice System}

This system is implemented in the background process in the server. Invoice automatically generated when the supplier accepts the order from the customer. First of all, whenever the supplier accepts the order from the customer then a 20 digit random string including character and number will be generated in the server. Such generated random number is the digital key of the transaction invoice. This signature is linked with the Transaction-ID so that whenever the customer wants to see his invoice he/she just need to access the link to the digital key send via the registered email. The system will access the digital key to find the transaction number and hence all the details will be shown. Furthermore, the customer can directly print the invoice.

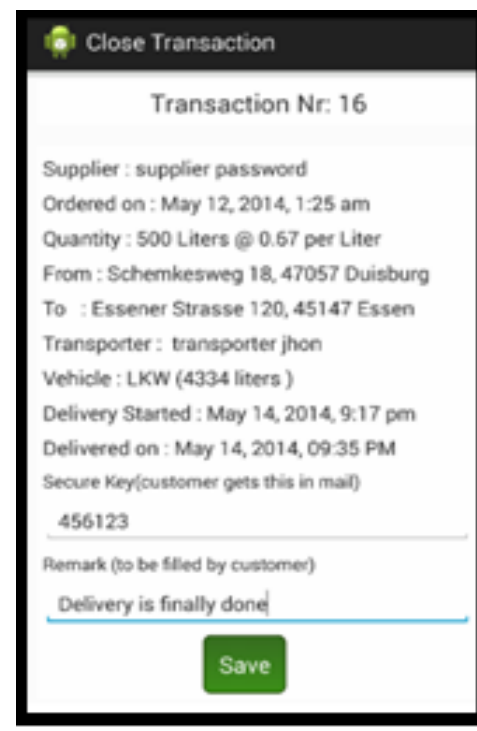

(a)

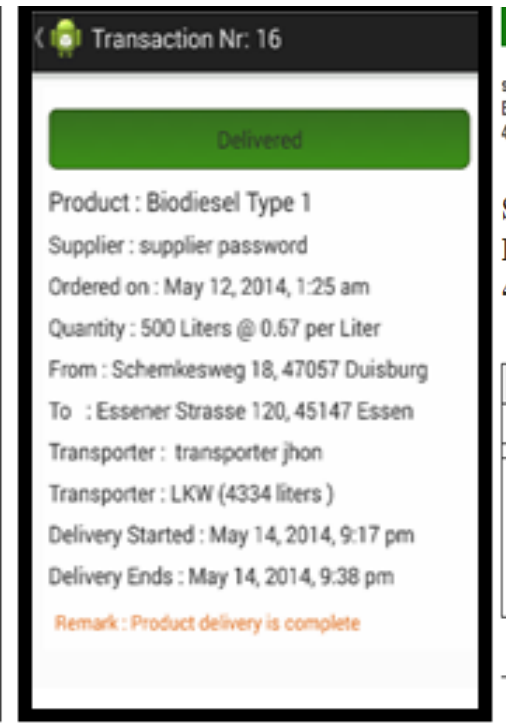

(b)

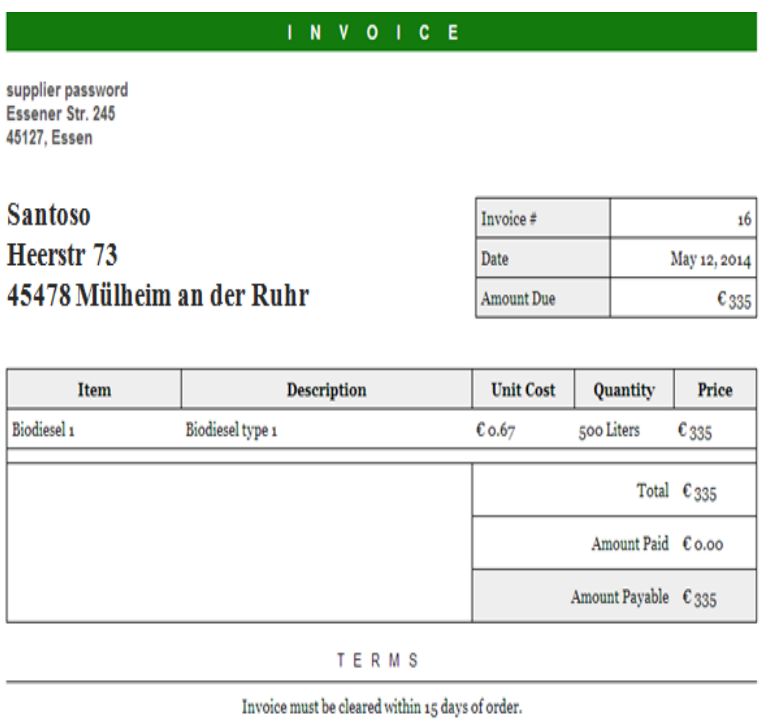

(c)

Figure 5 a) Close-Transaction, b) Transaction status, c) Invoice

The invoice will be again automatically generated for the transportation cost. When the transporter reaches the delivery destination then the customer needs to enter a security key in order to close the transaction (see Figure 5) and send it to the server then a new invoice will be auto generated for the transportation cost. The transportation cost is the cost of the transporter-vehicle multiplied by the total distance travelled by the transporter.

\subsection{Discussion \\ 4.2.1Flexibility}

The author has built an application based on the existing problem of Indonesian biodiesel supply chain as described in the chapter 1 and 2 . The transactions to be performed by this mobile-apps will cover B10-area as seen in the Figure 1. The author assumed that the following shared of information is really required on that point: 1)
Inventory-stock after biodiesel inline blending with petrodiesel, 2) Order-status from Industry or individual pumpstation, 3) Sales and trading status, 4) Quality monitoring, 5) Location-tracking, 6) Invoice and billing system, 7) Security aspects on biodiesel-distribution and 8) Communication protocols between supplier, transporter and consumer. This application also anticipates the growing of biodiesel into liberal market then biodiesel will openly supplied also by any private companies.

However, the propose-system will not only serve the only mentioned features because special requirements can be expanded based on the initial meeting of the biodiesel supply chain members such as such as raw-material suppliers, grain-transporters, biodiesel-producers, petrodiesel refinery stations, blending-stations, biodieselblending-transporters and pump-station owners. The members have also design the governance structure, rules and regulations, access management, and any other related 
issues of authentication or privacy. These initial steps are taken before the general software-system designed to ensure that the whole-system is fitted to the community vision. It would be flexible, whether it will be used to adjust the vertical or horizontally integrated manufacturer or implemented using push-pull supply chain strategy. The system also can be designed specifically to a contractual, transactional or relational governance of supply chain. All requirements can be customized in accordance to the agreement in the beginning include the terms of efficient logistic. Thereby, the principles of good governance e.g. Efficient, Accountable, Transparent, Responsive, Equitable and Inclusive could be fulfilled. All of this system ability emerges from the method that namely "Supply-Chain Software Development Process (SC-SDP)".

\subsubsection{Accreditation Board}

Existing biodiesel industry is usually buying finished products required for information- sharing. The products are somehow not necessarily purchased as needed. Meanwhile, this paper emphasizes on the system developments that match to the needs of business processes in the supply chain itself. Using this method, information sharing within a community can be customized and managed by a third party organization. The mobile-app could be used from the earlier phase of supply-chain, e.g. the feedstock plantation, cultivation, harvesting, and grain transport, etc. Overall, this method is suitable to be implemented on the real biodiesel industry and suggested to be used as the accreditation board of biodiesel which manages the entire supply, orders, trades and quality of biodiesel from upstream to the downstream (see Figure 6).

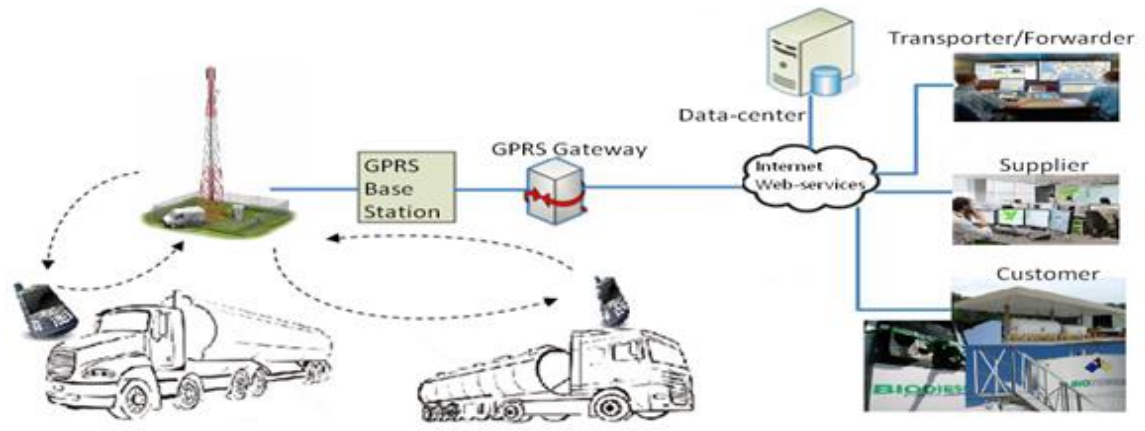

Figure 6 Biodiesel Accreditation Board Concepts using the Proposed-System

\subsection{Analysis 4.3.1Testing}

The application runs in a mobile device, thus the analysis of different technical aspects help in determining the actual behavior of the application in the target device and platform. The performance-analysis tests every menu of the mobile-app and records the processor and battery utilizations per-hour and data-consumptions. The performance also related to the battery usage, the processor usage of the mobile device and the data usage during transactions. In order to make the application friendly, extra features that needs more processor attention and kill the battery resources have been avoided. Based on the daily measurements from 4-7 July 2014, the processor and battery utilization can be concluded on the Table 1 .

Table 1 Processor and Battery Utilization

\begin{tabular}{|l|c|c|}
\hline Testing-condition & $\begin{array}{c}\text { Processor use per } \\
\text { hour }\end{array}$ & $\begin{array}{c}\text { Battery use per } \\
\text { hour }\end{array}$ \\
\hline With Location Service & $14.5 \%$ & $9 \%$ \\
\hline Without Location Service & $7 \%$ & $5 \%$ \\
\hline
\end{tabular}

The developed-application sends and receives data to the server back and forward every time. The server will manage flooding of the data from time to time. Hence, the data usage is another proper analyzing factor of this application. Since the application uses JSON data format which is very light weight and need less data traffic, a calculation of 50 to $100 \mathrm{Mb}$ of data usage has been made. The calculation is made by using and monitoring the "Data Usage" application available in android operating system.

Apart from the above mentioned analysis factors, a quick survey among the students have been made. There are
94 students have taken a part voluntarily from total 256 students who get the course of the Logistic-Simulation Laboratory for summer-semester 2014 in the Dept. Transport-system and Logistic, University Duisburg-Essen. Students who take experiments are offered to evaluate this apps. The invented-apps which observed using android emulator is assessed its performance on several evaluation indexes, i.e. Usability, User Friendliness, Security, Appearance, Reliability and Performance. Assessment is applying on the scale from 1 to 10 . The rating- value from 1 to 5 has been considered as "Need Improvements", 6 to 8 has been considered as "Average" and finally the rating above 8 has been considered as "Good". Figure 7 shows the graph of the collected data. The blue, red and green represent the respondent feedback in the area of Usability, User Friendliness, Security, Appearance, Reliability and Performance. The vertical axis expresses how many percentages of respondents who chose a particular value.

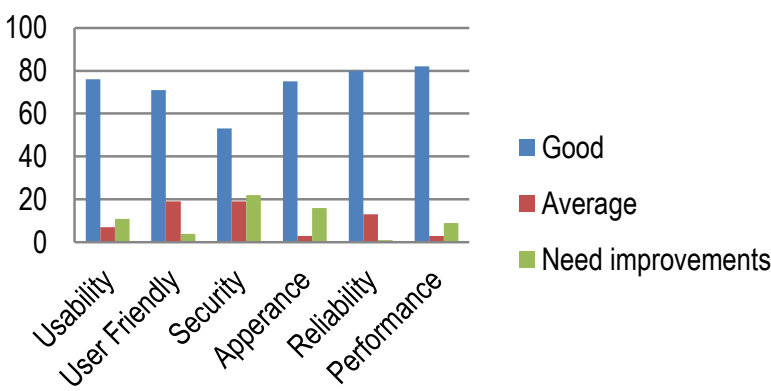

Figure 7 Survey Analysis Chart

The survey result has shown the potential of the apps to be implemented in the biodiesel distribution supply chain. 
It is recorded that there are many cumulative percentages of the respondents which give a "Good" rating-value in the field of Performance, Reliability, Usability, Userfriendliness and Appearance. The remaining problem to be considered is the security issue.

\subsubsection{Advantages and Shortcoming}

Lotfi (2013) gathers some positive impacts of information-sharing from Mourtzis (2011), Lee (2000), Lau (2002), Lee (2004), Fiala (2005), Li (2001), Yu (2001), Bagchi (2004), Li (2011), Jauhari (2009), Yang (2011), Marshall (2004) as follows: 1) Inventory reduction and efficient inventory management, 2) Cost reduction, 3) Increasing visibility (significant reduction of uncertainties), 4) Significant reduction or complete elimination of bullwhip effect, 5) Improved resource utilization, 6) Increased productivity, Organizational efficiency and improved services, 7) Building and strengthening social bonds, 8) Early problem detection, 9) Quick response, 10) Reduced cycle time from order to delivery, 11) Better tracing and tracking, 12) Earlier time to market, 13) Expanded network, 14) Optimized capacity utilization. Nevertheless, the benefits of information sharing that aforementioned are not easily obtained in the field of implementation.

There are some issues that commonly menace of information sharing as reviewed by Lotfi (2013) from Goodman (1998), Zhao (2002), Lee (1998), Khurana (2011), Fawcett (2008), Razavi (2006), Ardichvili (2003), Cetindamar (2005), Goodman (1998), Kim (2006) as follows: 1) Authentication and privacy, 2) Cost of information-shared 3) Rules and Governance, 4) The exactness and real time of information-shared, 5) Userfriendliness and effectiveness of information-shared.

Refers to the design, development-process, result, analysis and testing, it could be written that the proposedsystem match to the benefit as gathered by Lotfi (2013) in the matter of cost reduction, increasing visibility (significant reduction of uncertainties), significant reduction or complete elimination of bullwhip effect, improved resource utilization, increased productivity, organizational efficiency and improved services, quick response, reduced cycle time from order to delivery, better tracing and tracking, expanded network and optimized capacity utilization. It is also summarized that this mobile-application overcome some issues in the area of reducing cost of information-shared, gaining rules and governance, the exactness and real time of information-shared and user-friendliness-effectiveness of information-shared.

The remaining problem of this application is how to ensure that the information or data more secure to be shared and respect to the privacy.

\section{CONCLUSION}

A small step towards novel supply chain management of biodiesel has been developed which handles the transactions and distribution tracking using an application for mobile platform especially Android-OS. It is very essential and helps strengthening the product life cycle.

The developed-application makes the transaction more accurate, flexible, faster and reliable. The tracking-system increase visibility and the quality management ensure product quality. Performance analysis and survey proof that a better battery life has been shown. The usage of battery is $20 \%$ efficient than other client server based applications using the inbuilt battery check mechanism of the implemented platform. User survey provides higher ratings on performance, reliability, usability, appearance and userfriendliness. However, security is the remaining problems should be considered.

The apps can also be customized since there is flexibility during design phase. It can be expanded based on the initial meeting of the biodiesel supply chain members such as raw-material suppliers, grain-transporters, biodieselproducers, petro-diesel refinery stations, blending-stations, biodiesel-blending-transporters and pump-station owners. The members have also initially design the governance structure, rules and regulations, access management, and any other related issues of authentication or privacy. It would be also flexible, whether it will be used to adjust the vertical or horizontally integrated manufacturer or implemented using push-pull supply chain strategy. The system also can be designed specifically to a contractual, transactional or relational governance of supply chain. All requirements can be tailored in accordance to the agreement in the beginning include the terms of efficient logistic. Thereby, the principles of good governance i.e. Efficient, Accountable, Transparent, Responsive, Equitable and Inclusive could be fulfilled. All of this system ability emerges from the method that namely "Supply-Chain Software Development Process (SC-SDP)". Moreover, the proposed system is suggested to be integrated as the accreditation board of biodiesel which can help to manage the entire supply, orders, trades and quality of biodiesel from upstream to the downstream.

\section{REFERENCES}

Ardichvili, A., Page, V., Wentling, T. (2003). Motivation and barriers to participation in virtual knowledge-sharing communities of practice. Journal of Knowledge Management 7(1), pp. 64-77.

Awudu, I., Zhang, J. (2012). Uncertainties and sustainability concepts in biofuel supply chain management: A review. Renewable and Sustainable Energy Reviews 16(2), pp. 13591368.

Bagchi, P.K., Skjøtt-Larsen, T. (2004). Supply Chain Integration in Nordic Firms. 2nd World Conference on POM, Cancun, pp. $1-23$.

Bondioli, P., Gasparoli, A., Lanzani, A., Fedeli, E., Veronese, S., Sala, M. (1995). Storage Stability of Biodiesel. Journal of the American Oil Chemists' Society 72(6), pp. 699 - 702.

Cachon, G.P., Fisher, M. (2000). Supply chain inventory management and the value of shared information. Management Science 46(8), pp. 1032-1048.

Cetindamar, D., Catay, B., Basmaci, O.S. (2005). Competition through collaboration: insights from an initiative in the Turkish textile supply chain. Supply Chain Management: An International Journal 10(4), pp. 238-240.

CSCMP. (2014). Council of Supply Chain Management Professionals. Retrieved July 31, 2014, from CSCMP's Definition of Supply Chain Management http://www.clm1.org/about-us/supply-chain-managementdefinitions

Davenport, T.H., Brooks, J.D. (2004). Enterprise System and the Supply Chain. Journal of Enterprise Information and Management 17(1), pp. 8-19.

Fawcett, S.E., Magnan, G.M., McCarter, M.W. (2008). Supply chain alliances and social dilemmas: Bridging the barriers 
that impede collaboration. International Journal of Procurement Management 1(3), pp. 318-341.

Fiala, P. (2005). Information sharing in supply chains. Omega 33(5), pp. 419-423.

Goodman, P.S., Darr, E.D. (1998). Computer-aided systems and communities: Mechanisms for organizational learning in distributed environments. MIS Quarterly 22(4) , pp. 417-440.

Hsu, C.C., Kannan, V.R., Tan, K.C., Leong, G.K. (2008). Information sharing, buyer-supplier relationships, and firm performance: a multiregion analysis. International Journal of Physical Distribution \& Logistics Management 38(4), pp. 296-310.

Jain, S., Sharma, M.P. (2011). Long term storage stability of Jatropha curcas biodiesel. Energy 36(8), pp. 5409 - 5415.

Jauhari, V. (2009). Institutional Context for IT Use in the Automotive Industry: A Case Study on the Market Leader in India's Passenger Vehicle Sector. Technological Innovation Across Nations: Applied Studies of Coevolutionary Development, pp. 65-93.

Khurana, M.K., Mishra, P.K., Singh, A.R. (2011). Barriers to information sharing in supply chain of manufacturing industries. Int. Journal of Manufacturing System 1(1), pp. 929.

Kim, S., Lee, H. (2006). The Impact of Organizational Context and Information Technology on Employee KnowledgeüSharing Capabilities. Public Administration Review 66(3), pp. 370385.

Lau, J.S.K, Huang, G.Q., Mak, K. (2002). Web-based simulation portal for investigating impacts of sharing production information on supply chain dynamics from the perspective of inventory allocation. Integrated Manufacturing Systems 13(5), pp. 345-358.

Lee, H.L., So, K.C., Tang, C.S. (2000). The value of information sharing in a two-level supply chain. Management Science 46(5), pp. 626-643.

Lee, H.L., Whang, S. (2004). E-business and supply chain integration. The Practice of Supply Chain Management: Where Theory and Application Converge 62, pp. 123-138.

Lee, H.L., Whang, S. (2000). Information sharing in a supply chain. International Journal of Manufacturing Technology and Management 1(1), pp. 79-93.

Leung, D.Y.C., Kho, B.C.P., Guo, Y. (2006). Degradation of Biodiesel under different storage condition. Bioresource Technology 97(2), pp. 250-256.

Li, J., Shaw, M.J., Sikora, R.T., Tan, G.W., Yang, R. (2001). The effects of information sharing strategies on supply chain performance. College of Commerce and Business Administration, University of Illinois at Urbana-Champaign 34.

Li, Z., Gao, Y. (2011). Information sharing pattern of agricultural products supply chain based on E-commerce, in: 2011 International Conference on $\mathrm{E}$-Business and $\mathrm{E}$-Government (ICEE). Computer and Computing Technologies in Agriculture, pp. 539-548. Nanchang, China.

Lotfi, Z., Mukhtar, M., Sahran, S., Zadeh, A.T. (2013). Information Sharing in Supply Chain Management. Procedia Technology 11, pp. $298-304$

Marshall, C.C., Bly, S. (2004). Sharing encountered information: digital libraries get a social life. The 4th ACM/IEEE-CS joint conference on Digital Libraries get a social life (pp. 218227). Tuscon, Arizona: IEEE.

Mittelbach M., Gangl, S.. (2001). Long Storage Stability of Biodiesel Made from Rapeseed and Used Frying Oil. American Oil Chemical Society 78(6), pp. 573-577.

Monyem, A., Canakci, M., Gerpen, J.H. (2000). Investigation of Biodiesel Thermal Stability Under Simulated In-Use Conditions. Applied Engineering in Agriculture 16(4), pp. 373 - 378 .
Mourtzis, D. (2011). Internet based collaboration in the manufacturing supply chain. CIRP Journal of Manufacturing Science and Technology 4(3), pp. 296-304.

Nunes, M.B., Annansingh, F., Eaglestone, B. (2006). Knowledge management issues in knowledge-intensive SMEs. Journal of Documentation 62(1), pp. 101-119.

Pandey, V.C., Gark, S.K., Shankar, R. (2010). Impact of information sharing on competitive strength of Indian manufacturing enterprises: an empirical study. Business Process Management Journal 16(2), pp. 226-243.

PERTAMINA. (2012). Pengalaman dan Permasalahan Dalam Distribusi Biofuel. Anual-report . Jakarta: National Oil and Gas Mining Company of Indonesia - PERTAMINA.

Razavi, M.N., Iverson, L. (2006). A grounded theory of information sharing behavior in a personal learning space. CSCW '06 Proceedings of the 2006 20th anniversary conference on Computer supported cooperative work, New York, pp. 459-468.

Santoso, M.I., Noche, B. (2014). The evolution of smart web supply chain using intelligent governance system. The 4th Logistic and Maritim System Conference-LOGMS2014 (pp.112). Rotterdam: Erasmus University Rotterdam.

Serrano, M., Bouaid, A., Martinez, M., Aracil, J. (2013). Oxidation stability of biodiesel from different feedstocks: Influence of commercial additives and purification step. Fuel 113, p. 5058.

Simatupang, T.M., Sridharan, R. (2005). The collaboration index: a measure for supply chain collaboration. International Journal of Physical Distribution \& Logistics Management 35(1) , pp. 44-62.

Stock, J.R., Lambert, D.M. (2001). Strategic logistics management. Burr Ridge, Illinois: McGraw-Hill.

Taşyürek, M., Acaroğlu, M., Kahraman, A. (2010). The Effects of Storage Conditions on Viscosity of Biodiesel . Energy Sources Part A-recovery Utilization and Environmental Effects32(7), pp. 645-656.

Thompson, J. C., Peterson, C. L., Reece, D. L., Beck, S. M. (1998). Two-Year Storage Study with Methyl and Ethyl Esters of Rapeseed. ASAE Transaction 41, pp. 931-939.

Westbrook, S.R. (2005). An evaluation and comparison of test methods to measure the oxidation of neat biodiesel. Texas: National Renewable Energy Laboratory.

Wirawan, S.S. (2008). Biodiesel Untuk Industri: Penanganan dan Penyimpanan. Sosialisasi Biodiesel Pertamina . Semarang: BRDST - BPPT.

Wu, W., Chiag, C., Wu, Y., \& Tu, H. (2004). The influencing factors of commitment and business integration on supply chain management. Industrial Management \& Data System 104(4), pp. 322-333.

Yang, T.M., Maxwell, T.A. (2011). Information-sharing in public organizations: A literature review of interpersonal, intraorganizational and interorganizational success factors. Government Information Quarterly 28(2), pp. 164-175.

Yu, Z, Yan, H., Cheng, T.C.E. (2001). Benefits of information sharing with supply chain partnerships. Industrial Management \& Data Systems 101(3), pp. 114-121.

Zha, X, Ding, N. (2005). Study on information sharing in supply chain. Proceedings of the 7th international conference on Electronic commerce (ICEC '05), New York, pp. 787-789.

Zhang, G., Feldman, M., Peterson, C.L. (1988). Diesel engine durability when fueled with methyl ester of winter rapeseed oil. ASAE Paper No 88, pp. 1562.

Zhao, Y. (2002). The Impact of Information Sharing on Supply Chain Performance. Evanston, Illinois: Industrial Engineering and Management Sciences - Northwestern University. 
Muhammad Iman Santoso (ST., MSc.) is a PhD-candidate in the departement of Transport Systems and Logistics at the University of Duisburg-Essen. In addition to actively teaching the seminar and research at his insitute, he also ever taught at the Univ. Applied Science SRH Hamm. His research interests are: supply chain governance, logistic-network design, biofuel supply chain, information systems for supply chain management and simulation (operation-research). He has also been involved on several logistic projects in Germany and Indonesia such as warehouse design, port-analysis, supply chain monitoring and supply chain of alternative fuels.

Bernd Noche (Dr.-Ing, Dipl.-Ing) is a Professor in the field of Transport Systems and Logistics at the University of Duisburg-Essen. His research interests are: location planning in distribution logistics, acceptance of logistics systems, scheduling systems, simulation and planning of distribution centers, design of intermodal transport chains and monitoring of supply chain management systems. Besides teaching, for more than 25 years he is practising design and optimization of Supply Chain Management (SCM) projects in Europe, Asia and Latin America as a manager of the SimulationsDienstleistungs-Zentrum (SDZ) GmbH, one of prestigious SCM consultant in Dortmund. 